\title{
Green Business UMKM di Kota Depok
}

\author{
Hartono $^{\mathrm{a}, 1, *}$, Anita Maulina ${ }^{\mathrm{b}, 2}$, Noviandari ${ }^{\mathrm{b}, 3}$, Sukirno ${ }^{\mathrm{b}, 4}$, Muhammad Sholeh ${ }^{\mathrm{b}, 5}$ \\ a,b Institut Ilmu Sosial dan Manajemen Stiami \\ ${ }^{1}$ hartono@stiami.ac.id *; ${ }^{2}$ anita@stiami.ac.id ; ${ }^{3}$ noviandari@ stiami.ac.id ; ${ }^{4}$ sukirno@ stiami.ac.id ; 5 sholeh@stiami.ac.id \\ * corresponding author
}

ARTICLE INFO

Article History

Received,20-08-2020

Revised,10-01-2021

Accepted,17-01-2021

Keywords

Green Business;

MSMEs:

Depok City

\begin{abstract}
Depok is the smallest in west Java with such problems as garbage that pollutes several large rivers such as ciliwung and cisadane trash from small industries and communities, which can be reduced by umkm as the donor of $65 \%$ of the regional product.

Public service activities for umkm city depok endeavor to help umkm's doers to be more conscious of the environment by adopting green business.

It is known that most of the people involved in the depok city have low environmental awareness. Socializing can open up the insights of umkm doers to apply

Green business is his small business. By implementing green business, umkm perpetrators can also

Saves operating costs or production costs even promotional costs.

The reuse of reusable containers or the use of banana leaves in place of plastic containers adds to the traditional and unique value and to the culinary siri typical of depok cuisine. Such community service is to be expected to be an activity capable of carrying the city of depok as a friendly city or "friendly city."
\end{abstract}

\section{PENDAHULUAN}

\section{Analisis Situasi}

Kota Depok sebagai wilayah termuda di Jawa Barat memiliki luas wilayah sekitar 200,29 km2 dengan jumlah penduduk 2.254.513 jiwa pada 2017. Kondisi geografisnya dialiri oleh sungaisungai besar yaitu Sungai Ciliwung dan Cisadane serta 13 sub Satuan Wilayah Aliran Sungai. Disamping itu terdapat pula 25 situ atau danau. Data luas situ pada tahun 2005 sebesar 169,68 Ha, dengan kualitas air rata-rata buruk akibat tercemar (Depok, 2020). Selain memiliki masalah pada kualitas air, situ atau danau di wilayah Depok mengalami degradasi luasan. Hal ini disebabkan bertambahnya jumlah penduduk. Selain masalah kualitas air, luas wilayah lahan pertanian atau perkebunan juga sudah berkurang. Lahan yang dahulunya sawah atau kebun, sudah bertransformasi menjadi perumahan. Sampah dan limbah yang mencemari kualitas air dapat berasal dari rumah tangga maupun industri skala kecil atau UMKM yang sangat berkembang di Depok. Tercatat pada 2018 bahwa 65\% Produk Regional Bruto (PDRB) berasal dari UMKM (Fitri, 2018) dan didominasi oleh sektor kuliner dan fashion (Maulina \& Puspita, 2020). Saat ini pelaku UMKM Depok berjumlah sekitar 2.385 orang (Nurdiansyah \& Nur Aminah, 2019).

Depok dengan tagline Friendly City (Kotaraya, 2016), sudah seharusnya menjadi kota yang nyaman dan aman untuk dijadikan tempat tinggal. Namun, keadaan yang terjadi justru bertolakbelakang. Sampah dan limbah mendominasi sungai dan situ yang ada di Depok (Kumparan, 2020). Para pelaku UMKM harus menjadi pelopor gerakan Green Business demi mengembalikan wilayah Depok menjadi asri dan nyaman untuk ditinggali sesuai dengan ikon yang diusung kota Depok.

Penelitian (Astuti \& Catur Wahyuni, 2018) memberi kesimpulan bahwa implementasi Green Human Resource Management pada UMKM sangat perlu dilaksanakan. Hal ini didukung dengan adanya peran UMKM yang sangat penting bagi perkembangan ekonomi negara dan karakteristik UMKM yang bersifat padat karya. Namun demikian, proses implementasi green HRM perlu diawali dengan adanya kebijakan/ komitmen yang kuat dari pemilik UMKM untuk mengimplementasikan konsep tersebut. 
Besarnya kinerja Usaha Kecil dan Menengah dipengaruhi secara positif dan signifikan oleh Green Output, Green Marketing, dan Tingkat Kesadaran Masyarakat (Nur Utomo \& Rini Pratiwi, 2016). Harus ada sinergi antara masyarakat, perusahaan, media, pendidikan, dan pemerintah. Pelaku UMKM dan rumah tangga dapat menjadi ujung tombak suksesnya pelaksanaan green business karena UMKM adalah sektor pelaku ekonomi yang terbanyak yaitu sebesar 64\%. Karena dalam prakteknya green business mendapatkan beberapa kendala dalam pelaksanaannya. Salah satu upaya yang dapat dilakukan oleh pemerintah yaitu dalam menetapkan peraturan atau kebijakan yang mengatur tentang pelaksanaan green business.

Kesimpulan yang dibuat oleh (Borza \& Talmaciu, 2014) dalam penelitiannya tentang kewirausahaan bisnis hijau di daerah metropolitan di Romania adalah bahwa "The concern of entrepreneurs related to implementation of the environmental factors protection strategies are reduced just to the mandatory state, the orientation toward green businesses is limited and strategic projects for the next 5-10 years is extremely low targeting the specific practices of green economy". Dengan kata lain bahwa tingkat kepedulian para pelaku usaha (wirausahawan) hanya sebatas kewajiban saja.

Green Business yang ramai dibicarakan dan diimplementasikan di beberapa bidang bisnis menjadi topik yang dapat meluas. Setiap aspek bisnis dapat dijadikan konsep Hijau untuk melestarikan lingkungan. Salah satunya yaitu konsep mengenai Green Consumen Behaviour. Konsumen yang ada saat ini pun masih minim informasi tentang pentingnya pelestarian lingkungan. Hal ini dapat diantisipasi dengan gerakan Green Business yang dapat diimplementasikan pada UMKM kota Depok.

UMKM di Depok dapat menggerakan perilaku konsumen yang peduli terhadap lingkungan. Hal ini dapat dilakukan dengan berbagai cara, contohnya seperti mengganti kemasan plastik pembungkus dengan kemasan yang ramah lingkungan. Atau mengganti kemasan makanan atau minuman dengan kemasan yang dapat dipakai berulang kali. Namun hal ini belum umum di lakukan khususnya di kota Depok.

Pelaku usaha maupun konsumen masih belum terbiasa menggunakan kantong belanja ramah lingkungan, membawa botol minuman sendiri, tempat makan yang dapat dipakai berulang ketika membeli makanan dan minuman. Toko-toko penyedia bahan-bahan plastik pun banyak tersedia. Masih minimnya slogan-slogan peduli lingkungan atau sosialisasi tentang pentingnya memelihara lingkungan dari pemerintah kota sehingga masyarakat kota Depok pun belum memahami tentang pentingnya menjaga lingkungan.

Kegiatan Pengabdian Kepada Masyarakat ini akan bermanfaat bagi para pelaku UMKM. Penghematan biaya produksi, kesempatan menjual barang-barang yang ramah lingkungan, atau bahkan kesempatan untuk melakukan promosi secara tidak langsung dengan menggunakan wadah yang dapat dipakai berulang dengan merek yang ditempel juga merupakan salah satu bentuk promosi dan manfaat yang dapat diterima. Kegiatan ini juga sangat dibutuhkan oleh pelaku usaha dan rumah tangga di wilayah Depok, karena masih minimnya sosialisasi dan peraturan yang dikeluarkan oleh pemerintah kota Depok.

\section{Permasalahan Mitra}

Berdasarkan analisis yang telah dijelaskan di atas, maka dirumuskan permasalahan antara lain:

1. Minimnya informasi dan sosialisasi tentang peduli lingkungan di kalangan pelaku usaha dan konsumen.

2. Konsumen dan para pelaku usaha belum mengetahui strategi yang dapat digunakan untuk mengurangi limbah rumah tangga maupun limbah dan sampah hasil produksi.

3. Masih terlihat banyak sampah yang menumpuk di pinggir jalan di Kota Depok.

Oleh karena itu, program Pengabdian Kepada Masyarakat akan mengusung tema "Green Business UMKM di Kota Depok" dengan didukung kompetensi bidang Administrasi Bisnis khususnya bidang Inovasi dan Kreatifitas. Kegiatan ini bertujuan untuk memberikan pemahaman tentang pentingnya menjaga kebersihan sungai dan mencari alternatif pengganti wadah plastik sebagai pembungkus produk UMKM serta memberikan edukasi kepada pelaku UMKM di Kota Depok dalam menghemat biaya produksi dan promosi sebagai bagian dari Program Green Business. 


\section{PELAKSANAAN DAN METODE}

Kegiatan Pengabdian Kepada Masyarakat ini berlangsung pada hari Kamis tanggal 5 Maret 2020 mulai jam 10.00 WIB sampai dengan jam 12.00 WIB bertempat di Ruang Serbaguna Dinas Koperasi dan UKM Kota Depok yang berada di Gedung Balatkop Pemkot Depok Jl. Bahagia Raya, Abadijaya, Kec. Sukmajaya, Kota Depok, Jawa Barat. Kegiatan ini dihadiri oleh perwakilan Kepala Dinas Koperasi dan Usaha Mikro Kota Depok, 15 orang akademisi Institut Ilmu Sosial dan Manajemen STIAMI, 7 orang mahasiswa dan 20 orang pelaku UMKM Kota Depok.

Narasumber dan pendamping dalam kegiatan Pengabdian Kepada Masyarakat ini diantaranya yaitu:

1. Perwakilan Dinas Koperasi dan Usaha Mikro Kota Depok.

2. Dr. Hartono, SE, MM sebagai pemateri "Sosialisasi Sadar Lingkungan"

3. Anita Maulina, S.A.B., M.A sebagai pemateri "Tips \& Trik Go Green pada UMKM"

4. Tim Dosen Pendamping yang terdiri dari:

1) Noviandari Sari Utami., S.A.B., MA

2) Sukirno, S.A.B., M.A

3) Muhammad Sholeh., S.A.B., M.A

5. Perwakilan mahasiswa Institut Ilmu Sosial dan Manajemen STIAMI kampus Depok.

Agar tujuan pelaksanaan kegiatan PKM ini dapat berjalan sesuai dengan harapan, maka metode kegiatan yang ditempuh yaitu:

\begin{tabular}{|c|l|l|}
\hline No & \multicolumn{1}{|c|}{ Kegiatan } & \multicolumn{1}{|c|}{$\begin{array}{c}\text { Waktu } \\
\text { Pelaksanaan }\end{array}$} \\
\hline 1 & $\begin{array}{l}\text { Menyebarkan informasi tentang peduli lingkungan di kalangan } \\
\text { pelaku usaha dan konsumen. }\end{array}$ & Februari 2020 \\
\hline 2 & $\begin{array}{l}\text { Memperkenalkan konsep Green Business dan strategi yang dapat } \\
\text { ditempuh untuk mengurangi sampah dan limbah plastik dari hasil } \\
\text { produksi melalui ceramah dan forum diskusi. }\end{array}$ & 5 Maret 2020 \\
\hline 3 & $\begin{array}{l}\text { Melakukan survey tentang hal-hal yang dibutuhkan agar dapat } \\
\text { mengurangi limbah plastik. }\end{array}$ & 5 Maret 2020 \\
\hline 4 & $\begin{array}{l}\text { Melakukan pendampingan agar kegiatan Green Business dapat } \\
\text { diimplementasikan. }\end{array}$ & Maret - Juni 2020 \\
\hline
\end{tabular}

\section{HASIL DAN PEMBAHASAN}

Kegiatan PKM ini disambut dengan sangat baik. Dapat dibuktikan dengan tingkat antusiasme pelaku UMKM Kota Depok yang mendaftar untuk mengikuti kegiatan ini. Karena keterbatasan waktu dan tempat, maka peserta yang berasal dari pelaku UMKM dibatasi hanya 20 orang saja agar kegiatan pendampingan dapat berjalan sesuai dengan yang diharapkan. Para peserta menyimak paparan yang diberikan oleh pemateri dengan sangat baik. Hal ini dapat dilihat dari tertibnya kegiatan dan beberapa pertanyaan yang dilontarkan oleh peserta pelaku UMKM. Mereka antusias dalam memahami konsep Green Business dan bersedia untuk mengimplementasikannya dalam kehidupan sehari-hari. Sebagian besar dari mereka mendapatkan informasi tentang bagaimana cara menghemat biaya operasional melalui penghematan bahan bakar (gas), bahan habis pakai (minyak goreng, dll), cara membuat wadah makanan yang ramah lingkungan, serta memisahkan sampah.

Beberapa contoh penerapan Green Business dalam kehidupan berniaga setingkat usaha kecil yaitu:

1. Mengganti kemasan produk dengan wadah ramah lingkungan;

2. Menggunakan plastik pembungkus dengan bahan yang ramah lingkungan yaitu plastik berbahan dasar singkong atau rumput laut.

3. Menggunakan alat masak yang berkualitas sehingga dapat tahan lama (awet) dan terbuat dari stainless steel sehingga makanan dapat cepat matang.

4. Membersihkan kompor gas secara berkala dan menggunakan regulator dan selang gas sesuai dengan standar yang telah ditetapkan.

\section{Gambar 1 Daun Pisang Sebagai Alternatif Wadah Makanan Pengganti Plastik}




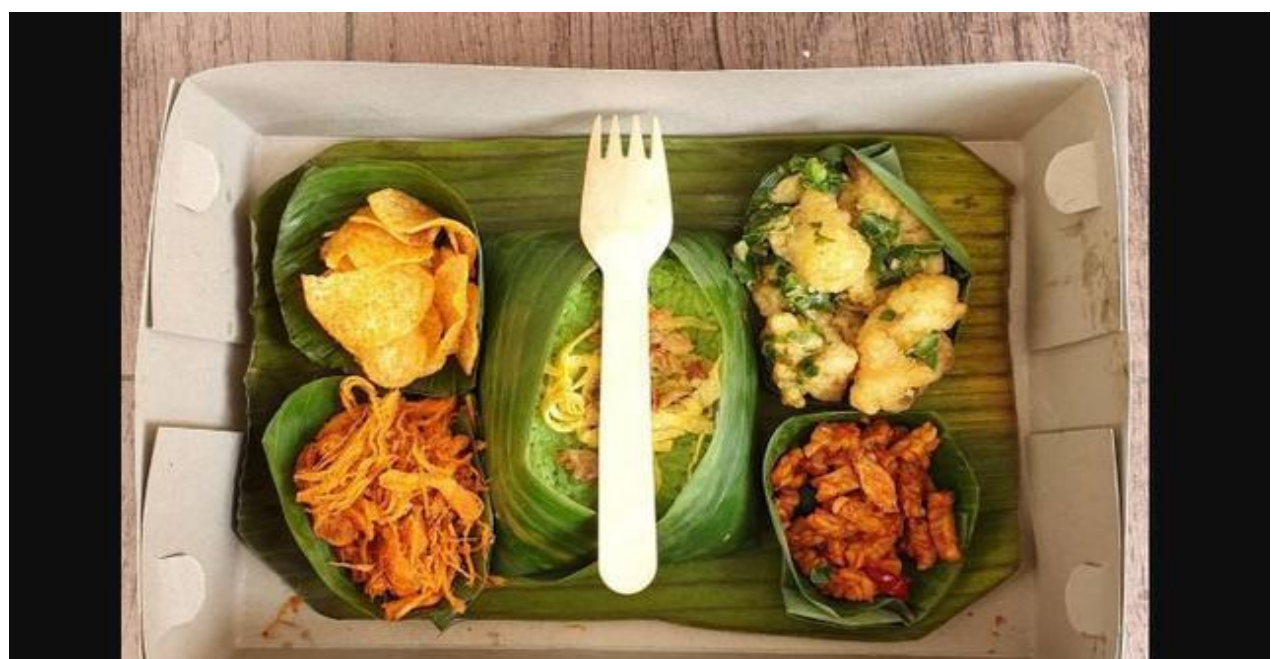

Sumber: www.liputan6.com (Mutiah, 2019)

Gambar 1 di atas adalah gambar wadah lauk dan sayur pada nasi box yang dapat diganti dengan daun pisang. Selain tampilannya menjadi lebih unik dan menarik, wadah yang berasal dari daun pisang ini juga membuat makanan menjadi lebih wangi dan semakin menggugah selera makan. Terdapat ciri khas makanan tradisional sehingga mampu menambah daya tarik dan minat pembeli.

\section{Gambar 2 Wadah Plastik yang dapat digunakan berulang}

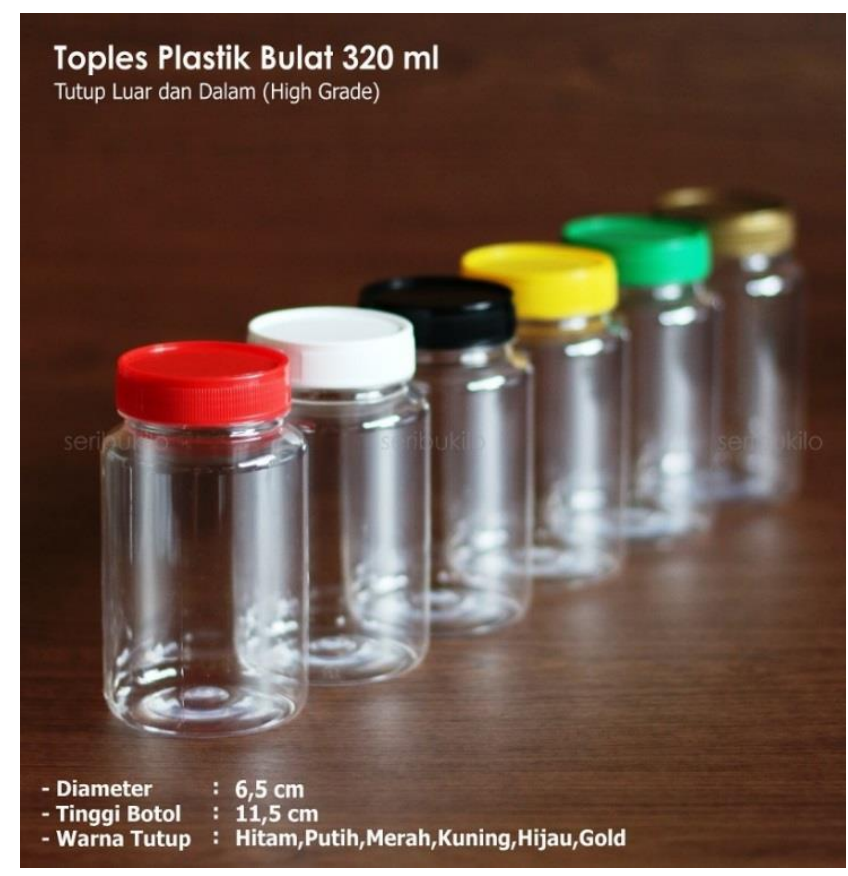

Sumber: www.shopee.com

Gambar 2 di atas adalah gambar wadah yang dapat dipakai berulang. Pengemasan produk makanan dalam wadah yang dapat dipakai berulang sangat menguntungkan bagi pelaku usaha. Wadah ini bisa diberi label atau stiker informasi produk makanan, nama toko, nomor telepon yang bisa dihubungi jika pembeli ingin memesan lagi. Tentunya dapat menekan lebih banyak biaya promosi jika dapat mencantumkan alamat media sosial.

\section{Gambar 3 Penyuluhan Konsep Green Business UMKM Kota Depok}




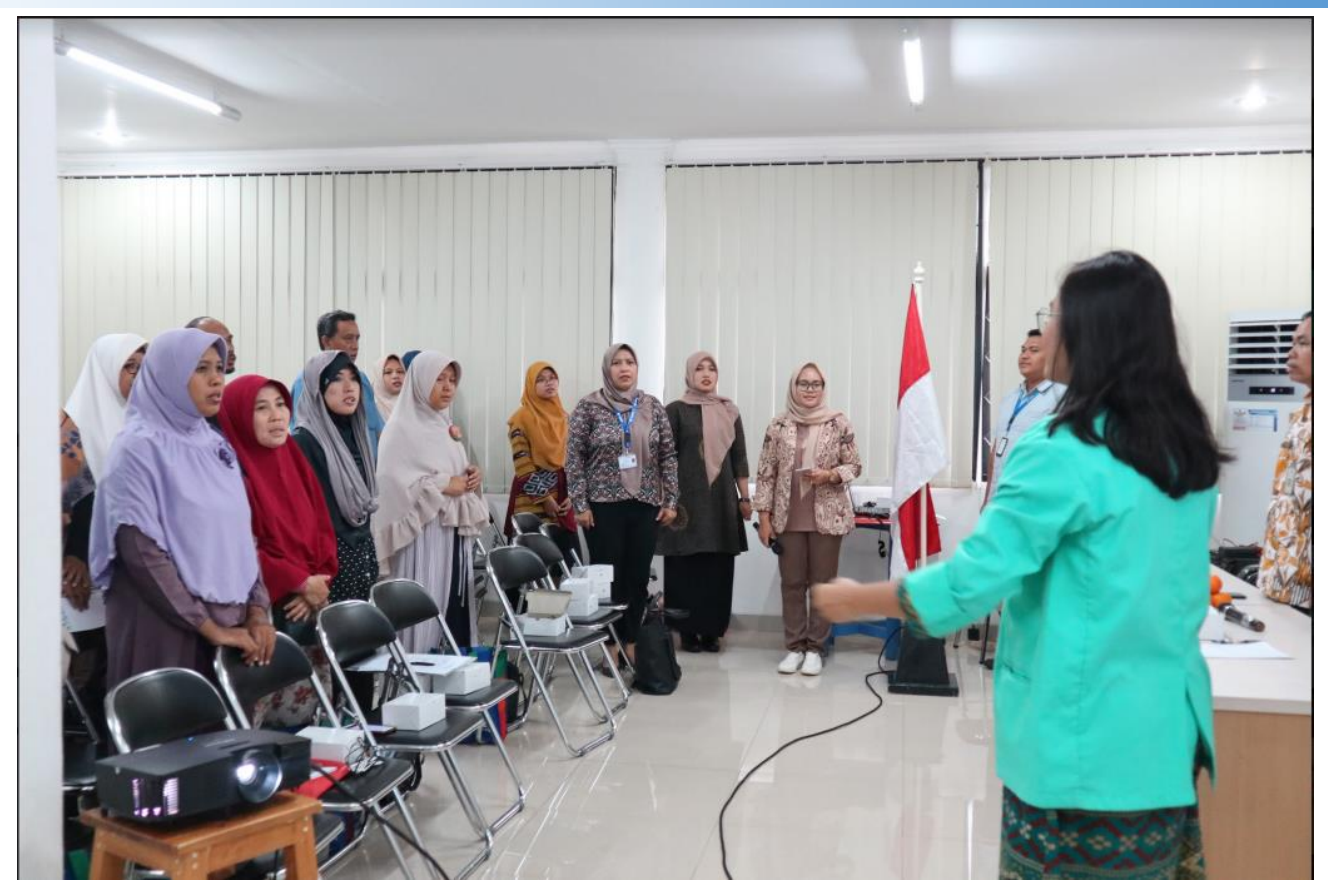

Sumber: data diolah 2020

Kegiatan Pengabdian kepada Masyarakat ini juga melibatkan mahasiswa aktif Institut STIAMI terutama mahasiswa dalam mata kuliah Kewirausahaan dan Kreatfitas \& Inovasi. Hal ini tentu sangat berguna bagi mahasiswa karena dapat mengetahui secara langsung permasalahan nyata yang terjadi di masyarakat sehingga dapat menemukan solusi yang implementatif untuk dikembangkan di kemudian hari.

\section{Gambar 4 Pendampingan Konsep Green Business UMKM Kota Depok}

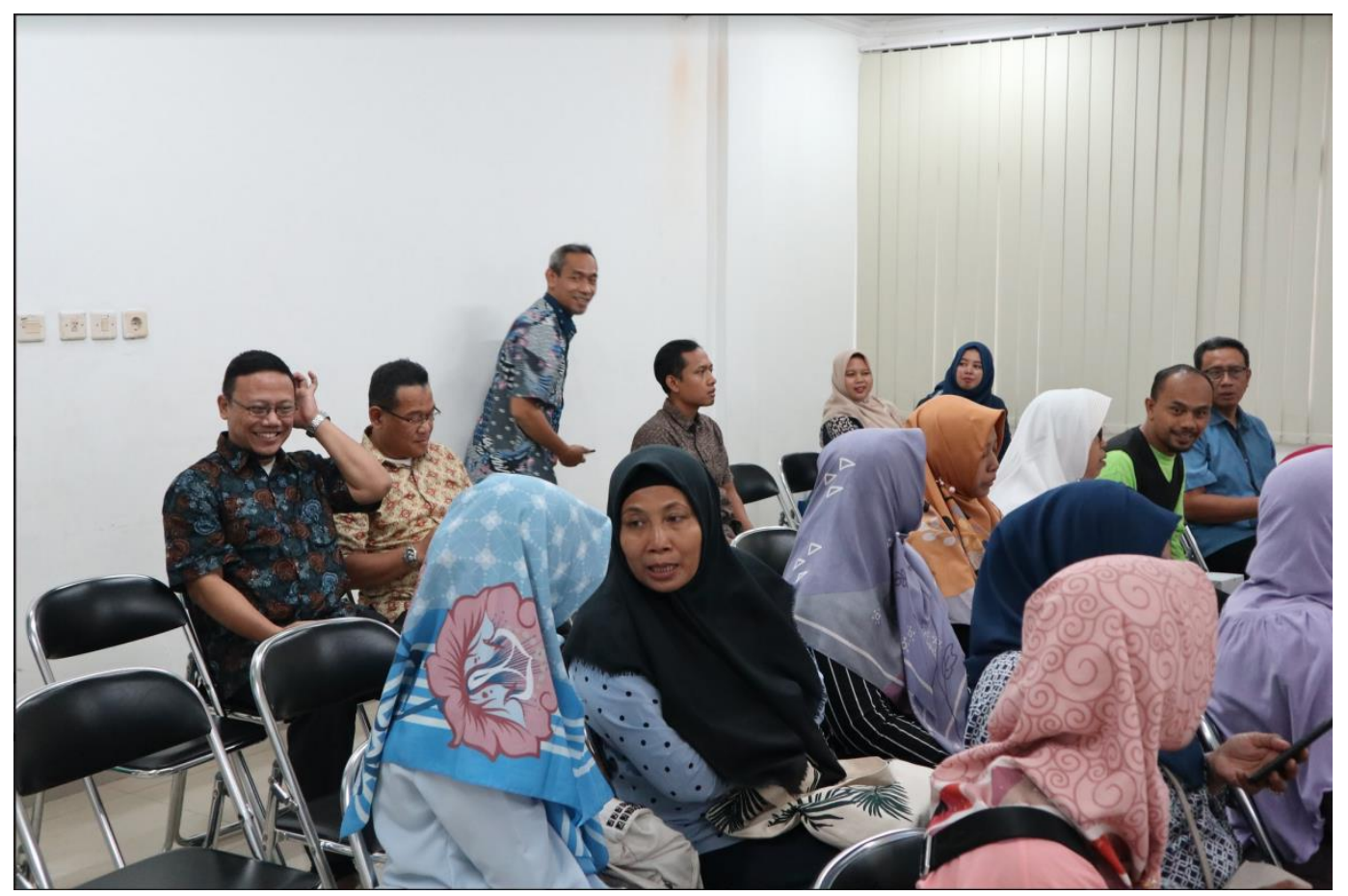

Sumber: Data diolah 2020 


\section{Gambar 5 Survey Kebutuhan Pelaku UMKM dalam Green Business}

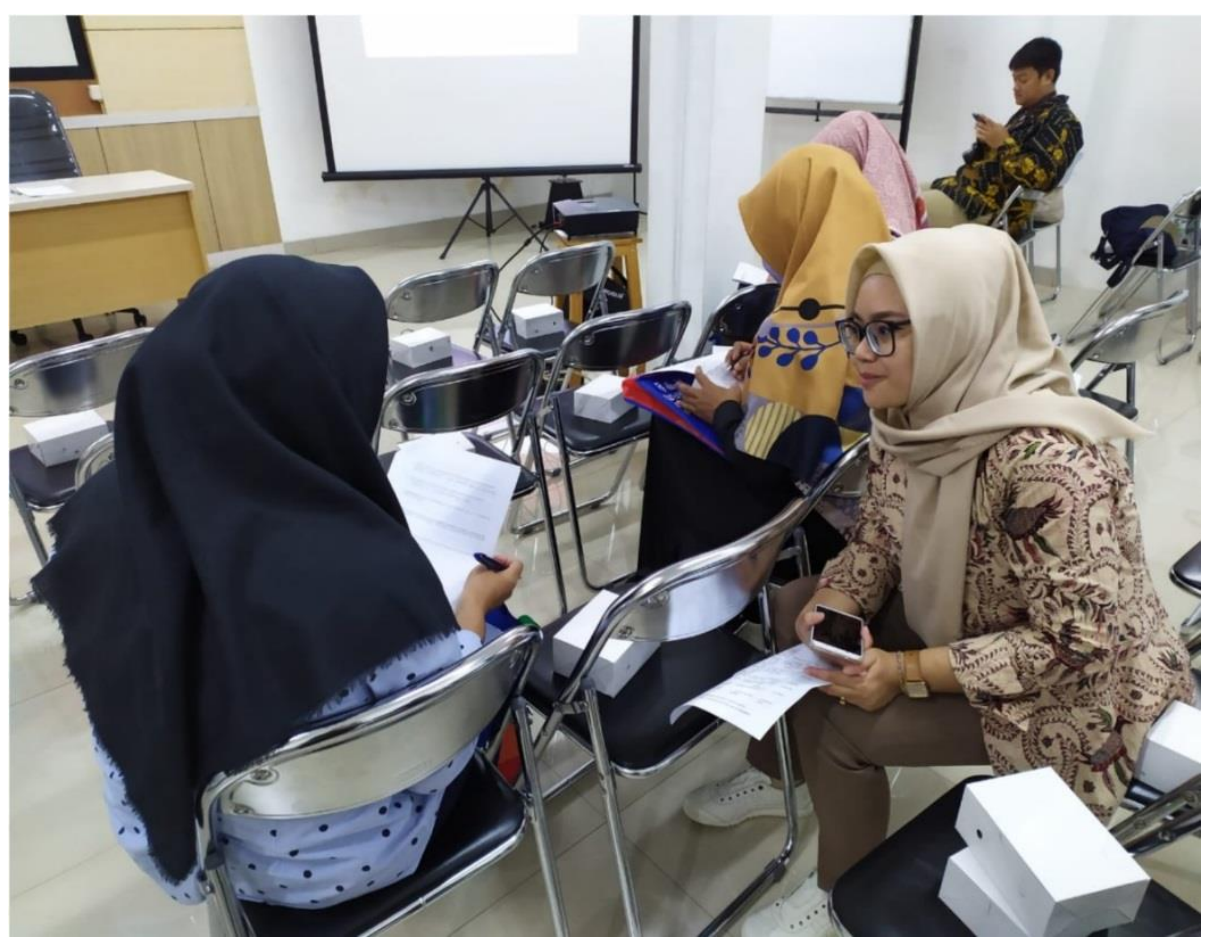

Sumber: Data diolah 2020

Gambar 4 dan 5 adalah gambar kegiatan pendampingan dosen dalam pemecahan masalah yang ada terkait dengan bisnis hijau. Hal ini diharapkan dapat berkelanjutan sehingga penerapan Green Business dapat terlaksana dengan baik.

\section{Gambar 6 Foto Bersama Pelaku UMKM Kota Depok dan Dinas Koperasi dan Usaha Mikro Kota Depok}

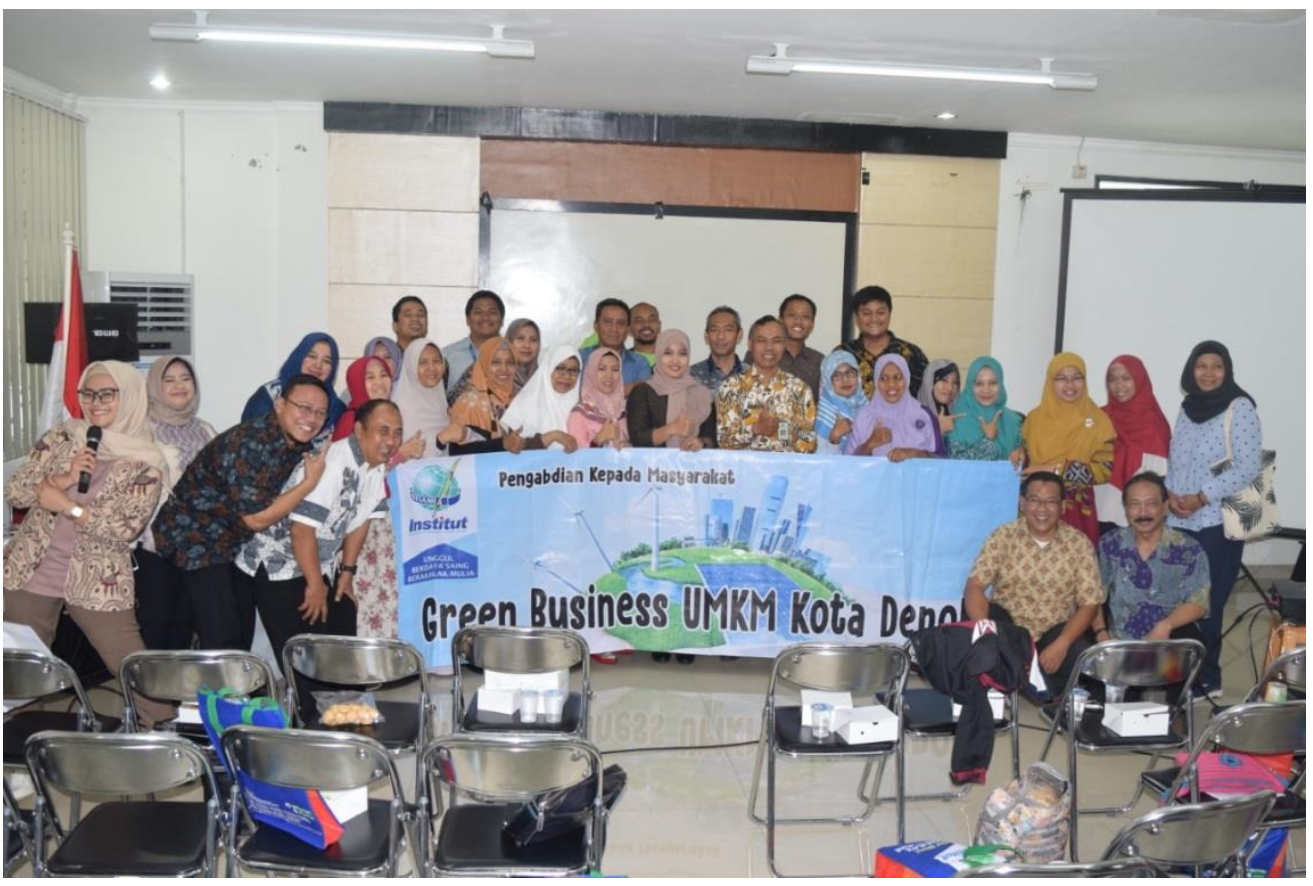

Sumber: Data diolah 2020

Gambar 6 merupakan gambar dari akhir kegiatan yang menandakan bahwa terdapat sinergitas antara Pemerintah Kota Depok, Perguruan Tinggi, Pelaku UMKM dan masyarakat demi terciptanya Depok sebagai kota Hijau. 


\section{PENUTUP}

\section{Simpulan}

Kegiatan Pengabdian Kepada Masyarakat ini terselenggara dengan baik dan lancar walaupun terdapat beberapa hambatan yang tidak signifikan. Keaktifan peserta pelaku UMKM selama kegiatan berlangsung menjadi bukti nyata bahwa kegiatan PKM seperti ini sangat dibutuhkan oleh pelaku UMKM. Mulai dari penyebaran informasi tentang konsep Green Business, memberikan tips dan trik tentang implementasi Green Business, penyebaran survey terkait masalah yang dihadapi serta mendampingi para pelaku UMKM dalam penerapan Green Business. Bertambahnya wawasan akan perkembangan dunia bisnis menjadi nilai tambah yang sangat berguna dalam memenangkan persaingan. Kegiatan PKM ini menjadi wadah bagi akademisi dalam mengaplikasikan ilmu pengetahuan. Sambutan yang hangat dan respon yang aktif membuat kegiatan ini memberi kesan mendalam bagi pelaku UMKM di Kota Depok dan semua orang yang terlibat.

\section{Saran}

Berdasarkan dari hasil evaluasi kegiatan Pengabdian Kepada Masyarakat ini, maka saran untuk kegiatan Pengabdian Kepada Masyarakat selanjutnya adalah:

1) Pihak Dinas Koperasi dan UMKM Kota Depok dapat menyediakan ruang yang lebih besar agar dapat menampung peserta yang lebih banyak lagi sehingga dapat menjangkau seluruh daerah di Kota Depok.

2) Mendatangi daerah-daerah perbatasan kota Depok dengan wilayah lain agar informasi Green Business dapat tersosialisasikan dengan baik dan menyeluruh.

3) Pemerintah Kota Depok dapat memberikan Sosialisasi secara rutin tentang sadar lingkungan.

4) Pemerintah Kota Depok dapat memberikan kemudahan dalam pengembangan bisnis online bagi pelaku UMKM.

\section{DAFTAR PUSTAKA}

Astuti, M., \& Catur Wahyuni, H. (2018). Strategi Implementasi Green Human Resource Management Pada Usaha Mikro, Kecil Dan Menengah (UMKM). Matrik, 12(2), 121-128. https://doi.org/https://doi.org/10.24843/MATRIK:JMBK.2018.v12.i02.p04

Borza, M., \& Talmaciu, M. (2014). Incidence of Green Business on Developing the Entrepreneurial Environment from Metropolitan Area of Iaşi. Procedia Economics and Finance, 15, 1201-1208. https://doi.org/DOI: 10.1016/S2212-5671(14)00579-6

Depok. (2020). Pemerintah Kota Depok. Depok.Go.Id.

Fitri, Y. (2018). Wow, UMKM Sumbang 65 \% Ekonomi Depok. Jabarnews.Com.

Kotaraya. (2016). Tagline Baru Kota Depok: A Friendly City. Depokrayanews.Com.

Kumparan. (2020). Hasil Ekspedisi Ciliwung Bima Arya: Depok Sumbang Sampah Terbesar ke Jakarta. Kumparan.Com. https://kumparan.com/kumparannews/hasil-ekspedisi-ciliwungbima-arya-depok-sumbang-sampah-terbesar-ke-jakarta-1uZfZx10v4g

Maulina, A., \& Puspita, M. (2020). Innovation Strategy of Small Medium Enterprise ( SME ) Through Public-Private Partnership in Depok City. 17(2), 230-235.

Mutiah, D. (2019). Boks Nasi Ramah Lingkungan, Sampah Terurai Tak Tunggu Ratusan Tahun. Liputan6.Com. https://www.liputan6.com/lifestyle/read/3972724/boks-nasi-ramahlingkungan-sampah-terurai-tak-tunggu-ratusan-tahun

Nur Utomo, M., \& Rini Pratiwi, S. (2016). Analisis Penerapan Green Business Terhadap Kinerja Ukm Di Kota Tarakan. Quality, 6(22), 143-150.

Nurdiansyah, R., \& Nur Aminah, A. (2019). Kontribusi UMKM Diharapkan Dapat Majukan Ekonomi Depok. National.Republika.Co.Id. 